\title{
Resistance of dentin coating materials against abrasion by toothbrush
}

\author{
Iori GANDOํㅗ ${ }^{1}$ Meu ARIYOSHI ${ }^{1}$, Masaomi IKEDA², Alireza SADR ${ }^{3}$, Toru NIKAIDO ${ }^{1}$ and Junji TAGAMI ${ }^{1,3}$ \\ ${ }^{1}$ Cariology and Operative Dentistry, Oral Restitution Department, Graduate School of Medical and Dental Sciences, Tokyo Medical and Dental \\ University, 1-5-45 Yushima, Bunkyo-ku, Tokyo 113-8549, Japan \\ ${ }^{2}$ Clinical Oral Science, Department of Oral Health Care Sciences, Faculty of Dentistry, Tokyo Medical and Dental University, 1-5-45 Yushima, \\ Bunkyo-ku, Tokyo 113-8549, Japan \\ ${ }^{3}$ Global Center of Excellence (GCOE) Program; International Research Center for Molecular Science in Tooth and Bone Diseases, Tokyo Medical \\ and Dental University, 1-5-45 Yushima, Bunkyo-ku, Tokyo 113-8549, Japan \\ Corresponding author, Toru NIKAIDO; E-mail: nikaido.ope@tmd.ac.jp
}

Thin-film coating of root dentin surface by all-in-one adhesives has been shown to be an effective option to prevent root surface caries. The purpose of this study was to investigate the wear resistance against toothbrush abrasion of two all-in-one coating materials; Shield Force (SF) and Hybrid Coat (HC). Bovine dentin surfaces were covered with one of the coating materials; SF or HC. After storage in water for $24 \mathrm{~h}$, the testing surface was subjected to the toothbrush abrasion test up to 50,000 cycles either in water or toothpaste slurry. The remaining thickness of the coating material was measured using SEM. Toothpaste slurry significantly increased rate of tooth brush abrasion of the coating materials. While SF and HC wore at a similar pace under toothbrush abrasion, SF had a thicker coat and could protect dentin longer, up to 50,000 cycles.

Keywords: All-in-one adhesive, Coating material, Wear resistance, Toothbrush, Surface roughness

\section{INTRODUCTION}

The growing geriatric population in many developing or developed countries is expected to retain their teeth into an old age. However, soft tissue recession due to aging, traumatic toothbrush habits, periodontal disease or surgical periodontal treatment will unavoidably result in exposure of susceptible root surface ${ }^{1)}$ and higher risk of root caries and dentin hypersensitivity. Prevention of primary root caries is attempted mainly by the daily use of fluoride-containing mouth rinse $\mathrm{e}^{2,3)}$ or toothpaste ${ }^{2,4)}$. While this treatment is cost-effective and less stressful to the patient, success depends upon the compliance of patients. In this regard, simple single-visit methods to protect the exposed root surfaces from caries attack in the long-term are advantageous ${ }^{5)}$.

Thin-film coating materials have been developed through the technology of all-in-one adhesive systems; the coatings were used to seal the exposed dentin after cavity and crown preparation ${ }^{6}$. It was also reported that the thin-film coating with an all-in-one adhesive system could prevent marginal leakage beneath full cast crown $^{7)}$ and improve the bond strength of resin cement to dentin ${ }^{8-10)}$. While the use of various resin-based restorative materials ${ }^{5}$ have been suggested as protective layers for exposed dentin surfaces, a durable thinfilm coating should bear advantages over conventional restoration procedures in terms of minimal invasiveness, ease of application and reduced complications associated with restoration margins ${ }^{11)}$. In addition, application of the all-in-one adhesives to dentin creates the acid-base resistance zone beneath the hybrid layer ${ }^{12)}$, which is a reinforced dentin, so called "Super Dentin" to resist against caries attack ${ }^{13}$. Thin-film coating of root dentin surface by using an all-in-one adhesive reportedly prevented demineralization by acid attack to the root dentin surface and reduced biofilm attachment formation on to surface ${ }^{14,15}$. Covering the exposed dentin surfaces using the coating materials and sealing tubules can also potentially reduce dentin hypersensitivity ${ }^{16)}$. The coating should be the most beneficial option for the patients, as they can be performed as a single-visit treatment, provided that their effects last for a long-time.

On the other hand, toothbrushing may be responsible especially for wear of cervical restorations ${ }^{17}$. The wear resistance of the coating materials on root surface is of great clinical significance; the success of this simple treatment literally depends on the durability of the coating materials on the dentin surface. Although a number of studies have described wear resistance of restorative materials to toothbrush abrasion ${ }^{18-20)}$, a limited number of studies have been conducted on the wear of the coating materials. Therefore, the purpose of this study was to investigate the wear resistance of two all-in-one coating materials against toothbrush abrasion. In addition, the hardness and surface roughness of the coating materials were evaluated. The null hypothesis of this study was that toothbrush wear of the coating materials were not affected by materials, toothbrush abrasion cycles and abrasion media.

\section{MATERIALS AND METHODS}

Materials used in this study

Two coating materials; Shield Force (SF, Tokuyama Dental, Tokyo, Japan) and Hybrid Coat (HC, Sun Medical, Moriyama, Japan) were used in this study. The compositions of these coating materials are shown in 
Table 1. SF is a single-bottle all-in-one adhesive system, which contains three dimensional self-reinforcing (3DSR) monomer and glass fillers. The several phosphate groups of the 3D-SR monomer are capable to interact with calcium at multiple sites and form ionic bonds. SF has been developed as a coating material for reduction in dentin hypersensitivity. $\mathrm{HC}$ is also an all-in-one adhesive system, which is composed of an adhesive and a sponge. The adhesive contains 4-methacryloxyethyl trimellitate anhydride (4-META) as a functional monomer. The sponge supplied by the manufacturer contains co-activators, such as p-toluene sulfinate salt and amine, which promote interfacial polymerization. $\mathrm{HC}$ was developed as a resin coating material to protect dentin prepared for indirect restorations ${ }^{8)}$.

\section{Specimen preparation}

The specimen preparation procedure is schematically illustrated in Fig. 1. One-hundred twenty eight freshly extracted bovine incisors, stored frozen were used as the test substrates. A flat superficial dentin surface was prepared by trimming labial enamel using a model trimmer (Y-230, Yoshida, Tokyo, Japan) under copious water lavage. The roots were then removed and each tooth specimen was trimmed to obtain a dentin block $8 \times 10 \times 3 \mathrm{~mm}$ in size. The blocks were embedded in a methylmethacrylate resin (Unifast III, GC, Tokyo, Japan). Afterwards, the specimen surface was wetpolished with \#4000-grit silicon carbide paper followed by rinsing in deionized water for 1 min to obtain a smooth dentin surface as a base for measuring thickness of the coating material. Following this, the specimens were randomly divided into two groups. The dentin surface in each group was covered with a single coat of one of the coating materials (SF or $\mathrm{HC}$ ) using the sponge supplied in the package, according to the manufacturers' instructions. Table 1 summarizes the compositions and application instructions for each material. A halogen light curing unit at an output intensity of $500 \mathrm{mw} / \mathrm{cm}^{2}$ (Optilux 501, Demetron-Kerr, Danbury, CT, USA) was used to polymerize the coating material. After storage in distilled water at $37^{\circ} \mathrm{C}$ for $24 \mathrm{~h}$, the surfaces of the specimens were covered by a masking tape (Plastic Tape, Asahipen, Osaka, Japan) with the exception of the central $2 \times 10 \mathrm{~mm}$ window. The masking tape protected the original flattened surface of the coating material from abrasion for thickness measurements after abrasion.

\section{Toothbrush abrasion test}

Testing surface of each specimen was subjected to the toothbrush abrasion test. The test was performed in an automatic brushing machine (K236, Tokyo Giken, Tokyo, Japan). The coated specimens were divided into two subgroups; the specimens were abraded either in toothpaste slurry prepared by mixing $100 \mathrm{~g}$ of a regular toothpaste (White and White, Lion, Tokyo, Japan) in 700 $\mathrm{mL}$ of tap water (S), or in $700 \mathrm{~mL}$ of tap water (NS). Prospec-Plus (GC, Tokyo, Japan) toothbrushes $(23 \mathrm{~mm}$ in length, $8 \mathrm{~mm}$ in width, medium hardness, $9.5 \mathrm{~mm}$ in filament length) were used. The toothbrushes were fixed at the holder of the brushing machine, allowing movement of the brush head parallel to the coated surface of the specimens at a rate of 100 cycles per min. Each cycle consisted of two straight $10 \mathrm{~mm}$ strokes along the longer side of the exposed window under a load of $300 \mathrm{~g}$ placed on the center of the holder. Eight specimens were prepared respectively for each period; 1,000, 10,000, 20,000 or 50,000 cycles. The toothpaste slurry was renewed after every 10,000 cycles. After each period, the specimen was removed from the storage container, and thickness of the coating material was confirmed as described below.

\section{Thickness measurement}

After the toothbrush abrasion test, the masking tape on the specimens was peeled off and the coated surface

Table 1 Coating materials used in this study

\begin{tabular}{|c|c|c|c|c|c|}
\hline Code & Brand Name & Manufacturer & Batch No. & Composition & Application instructions \\
\hline $\mathrm{SF}$ & Shield Force & $\begin{array}{l}\text { Tokuyama } \\
\text { Dental, } \\
\text { Tokyo, } \\
\text { Japan }\end{array}$ & 051060 & $\begin{array}{c}\text { 3D-SR monomer, HEMA, } \\
\text { TEGDMA, Bis-GMA, } \\
\text { Glass filler, Isopropyl alcohol, } \\
\text { Photoinitiator, Water }\end{array}$ & $\begin{array}{c}\text { Apply the coating material } \\
\text { for } 20 \mathrm{~s} \\
\text { Mild air-blow for } 5 \mathrm{~s} \text { and strong } \\
\text { air-blow for } 5 \mathrm{~s} \\
\text { Light-cure for } 10 \mathrm{~s}\end{array}$ \\
\hline $\mathrm{HC}$ & Hybrid Coat & $\begin{array}{l}\text { Sun Medical, } \\
\text { Moriyama, } \\
\text { Japan }\end{array}$ & TE3 & $\begin{array}{c}\text { Liquid: 4-META, } \\
\text { Monomethacrylate, } \\
\text { Photoinitiators, Stabilizers, } \\
\text { Polyfunctional acrylate, } \\
\text { Acetone, Water } \\
\text { Cata-brush: p-toluene } \\
\text { sulfinate salt, Amine }\end{array}$ & $\begin{array}{l}\text { Apply the coating material } \\
\text { for } 20 \mathrm{~s} \\
\text { Mild air-blow for } 5 \mathrm{~s} \text { and } \\
\text { strong air-blow for } 5 \mathrm{~s} \\
\text { Light-cure for } 10 \mathrm{~s}\end{array}$ \\
\hline
\end{tabular}

3D-SR monomer: three dimensional self-reinforcing monomer; HEMA: 2-hydroxyethyl methacrylate; Bis-GMA: BisphenolA-diglydidyl methacrylate; TEGDMA: triethyleneglycol dimethacrylate; 4-META: 4-methacryloyloxyethyl trimellitate anhydride 


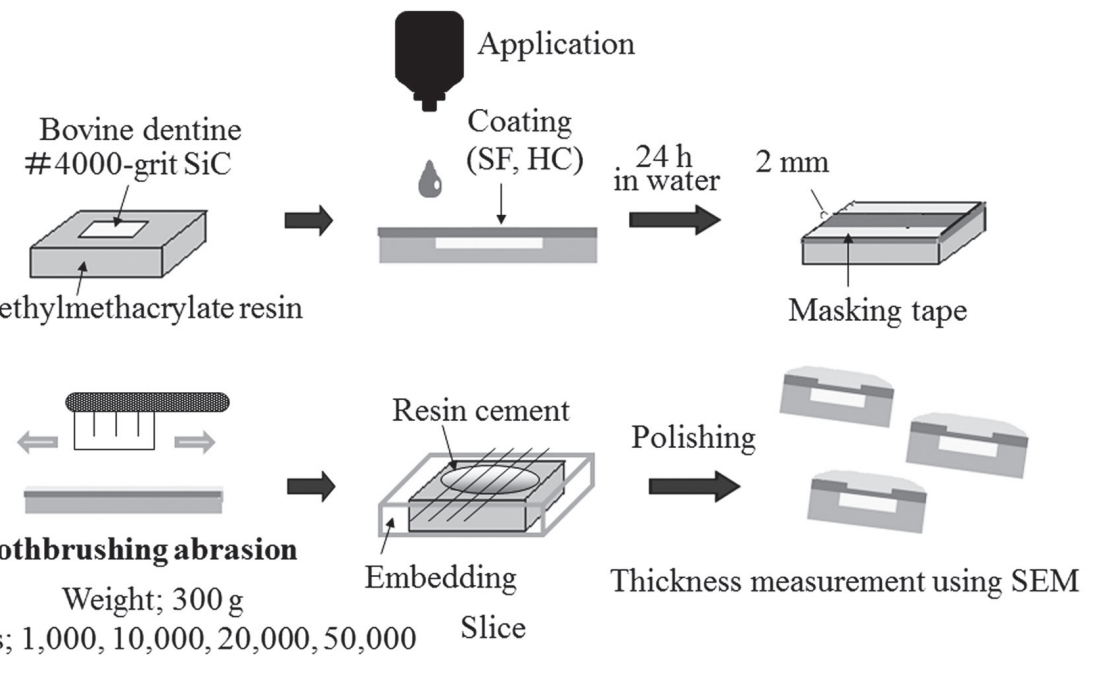

Fig. 1 Schematic illustration of sample preparation for toothbrush abrasion test in the study.

was rinsed under running water for $15 \mathrm{~s}$. The specimen was then sonicated in deionized water for $5 \mathrm{~min}$. A resin cement (Bistite II, Tokuyama Dental, Tokyo, Japan) was applied on the surface of the specimen in order to prevent wear the outer edge of the coating material during the polishing procedures. After curing of the resin cement, the specimens were embedded in epoxy resin (Epon 815, Nissin EM, Tokyo, Japan).

Each specimen was then sectioned perpendicular to the coating material-dentin interface using a low-speed diamond saw (Isomet, Buehler, Lake Bluff, IL, USA) under running water to yield three slices. The cross-sectional surfaces of the slices were polished consecutively up to \#1200-grit SiC paper, followed by diamond pastes (6, 3, 1, and $0.25 \mu \mathrm{m}$; DP-Paste, Struers A/S, Copenhagen, Denmark). After each step, the specimens were cleaned ultrasonically in distilled water for $2 \mathrm{~min}$. Finally, the fine polished specimens were dried at room temperature for $24 \mathrm{~h}$ and gold sputter-coated for SEM (JSM-5310LV, JEOL, Tokyo, Japan) observations.

The remaining thickness of the coating material after toothbrush abrasion was measured using SEM. Two points selected from abrasion area were each 100 $\mu \mathrm{m}$ from the midpoints. Two points selected from the non-abrasion area were each $100 \mu \mathrm{m}$ from the boundary between abrasion area and non-abrasion area (Fig. 2). The mean value of thickness of the coating layer was calculated for each cycle $(n=8)$.

\section{Nanoindentation test}

Cross-sectional hardness of each coating material before abrasion was determined using a nanoindentation system (ENT-1100a, Elionix, Tokyo, Japan). Three additional specimens were prepared in the same manner as described for thickness measurement, with the exception of final dehydration and the sputter-coating step.

The coating materials were indented using a

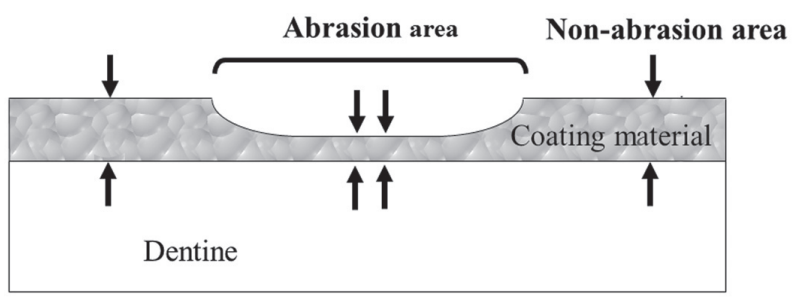

Fig. 2 The remaining thickness of coating materials was measured using SEM at the two points, selected from non-abrasion area and abrasion area each (bold arrows).

Berkovich diamond indenter with an enclosed angle of $130^{\circ}$ at a constant loading rate of $0.1 \mathrm{mN} / \mathrm{s}$ up to a maximum load of $1.5 \mathrm{mN}$. The temperature of the testing chamber was held constant at $28^{\circ} \mathrm{C}$. Ten indentations were made at the midpoint of the coating layer for each specimen at $5 \mu \mathrm{m}$ intervals $(n=30)$.

\section{Surface roughness analysis}

Change in surface roughness of the coating materials before/after toothbrushing was evaluated. The specimen preparation was carried out in the same manner as described for the toothbrush abrasion test. The non-abraded specimens and the abraded specimens subjected to toothbrushing for 10,000 cycles were used for this purpose. In addition, bovine dentin specimens polished with \#4000-grit SiC were used as a smooth dentin surface control for the roughness comparisons. Surface roughness of each specimen was analyzed along three lines by using a confocal laser scanning microscope (1LM21H/W, Lasertec, Yokohama, Japan) under $\times 200$ magnification. Three specimens were tested for each group $(n=9)$. 


\section{Statistical analysis}

All data were subjected to Kolmogorov-Smirnov test to confirm the normality required for the parametric comparisons. Data of thickness within each coating material were analyzed by two-way analysis of variance (ANOVA) to examine interaction between abrasion media and number of toothbrush abrasion cycles, followed by the $t$-test with Bonferroni correction. The relationship between the test cycles beyond the initial 1,000 cycles and the thickness of the coating layer under each abrasion media was analyzed by regression analysis. The slopes of linear regression were compared between the two coating materials by analysis of covariance (ANCOVA).

The data for nanoindentation hardness of the coating materials were analyzed by a Student's $t$-test. The data for surface roughness of the coating materials were analyzed by one-way analysis of variance (ANOVA) and the $t$-test with Bonferroni correction. All statistical procedures were performed in the SPSS software (SPSS, Chicago, IL, USA) at a $95 \%$ level of confidence $(\alpha=0.05)$.

\section{RESULTS}

\section{Thickness of the coating materials}

Mean thickness of the coating materials was shown in Fig. 3. The typical SEM observations of the coating materials after 10,000 cycles of abrasion were revealed in Fig. 4. Since the coating in HC/S group was worn away before 50,000 cycles of toothbrush abrasion and dentin surface was exposed, thickness of the coating material could not be measured. Therefore, this group had to be excluded from the statistical analysis.

The average thicknesses of SF and HC before toothbrush abrasion testing were approximately $12 \mu \mathrm{m}$ and $6 \mu \mathrm{m}$ respectively. However, thickness of the coating material decreased with increased cycles of toothbrushing $(p<0.05)$. Wear resistance of the coating materials was significantly influenced by the abrasion media, being water or slurry with the toothpaste $(p<0.05)$.

The tendencies for the decrease of thickness in the coating materials were divided into two patterns; 0-1,000 cycles and 1,000-50,000 cycles, which may be due to the initial presence of the oxygen-inhibited

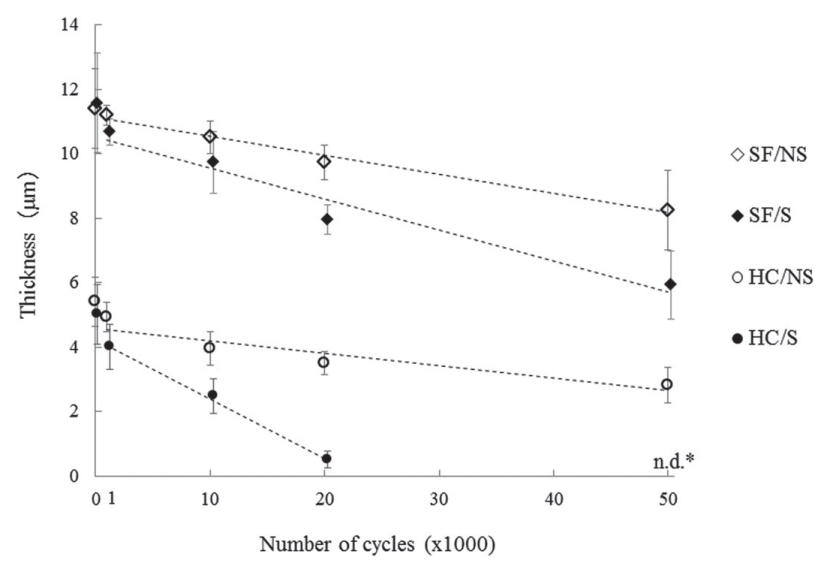

Fig. 3 Relationship between the thickness of the coating materials and the cycles of toothbrushing. The graph represents the mean and standard deviation of thickness, together with a simple linear regression of the four groups beyond 1,000 cycles $(n=8)^{*}$. n.d.; HC/S was worn out and could not be measured at 50,000 cycles.

$\mathrm{SF} / \mathrm{NS} ; \mathrm{y}=-0.059 \mathrm{x}+11.1, \mathrm{R}^{2}=0.99(p<0.0001)$; $\mathrm{SF} / \mathrm{S} ; \mathrm{y}=-0.096 \mathrm{x}+10.5, \mathrm{R}^{2}=0.96(p<0.0001)$; $\mathrm{HC} / \mathrm{NS} ; \mathrm{y}=-0.038 \mathrm{x}+4.6, \mathrm{R}^{2}=0.86(p<0.0001)$; $\mathrm{HC} / \mathrm{S} ; \mathrm{y}=-0.184 \mathrm{x}+4.2, \mathrm{R}^{2}=1.00(p<0.0001)$

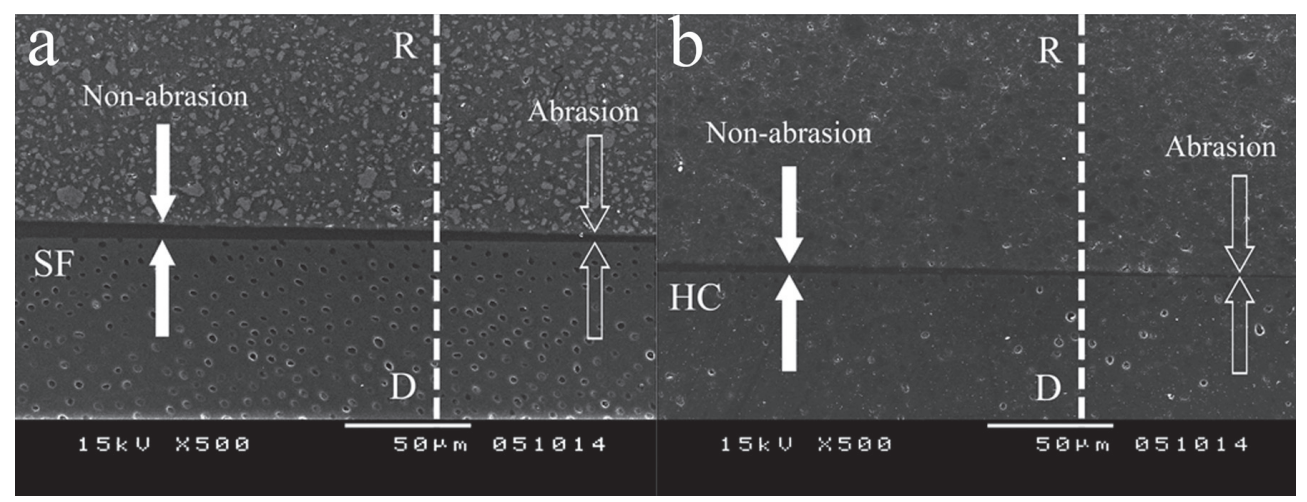

Fig. 4 Cross-sectional SEM micrographs showing the coating materials after 10,000 cycles of brushing $(\times 500)$.

The dashed-lines indicate the border of the tape covering non-abrasion area as the original surface. At the boundary of abrasion area and non-abrasion area, the surface of coating material was worn in slope rather than a sharp step. The thickness of coating after abrasion (between two blank arrows) is visibly lower than that before abrasion (between two bold arrows). SF (Shield Force) consistently showed higher thickness compared to HC (Hybrid Coat). D: dentine, R: resin cement (for SEM preparation). 
unpolymerized layer on the cured coating materials (Fig. 3). ANCOVA analysis of the regressions in Fig. 3 indicated that tendencies of the toothbrush wear of each coating material abraded under any of the abrasion media were not significantly different $(p>0.05)$.

\section{Nanoindentation test}

The mean nanoindentation hardness values of the coating materials were listed in Table 2. The values for SF and HC were 295.4 and 283.9 MPa, respectively, in which there was no significant difference between the two coating materials $(p>0.05)$.

\section{Surface roughness}

The mean surface roughness values of the coating materials and polished bovine dentin were summarized in Table 3. In the coating groups, one-way ANOVA and $t$-test with Bonferroni correction indicated that surface roughness of the coating surface after toothbrush abrasion for 10,000 cycles was significantly higher than that of the original surface before abrasion test $(p<0.05)$. However, there was no significant difference in surface roughness between $\mathrm{SF}$ and $\mathrm{HC}$ either before or after abrasion $(p>0.05)$. Surface roughness values of SF and $\mathrm{HC}$ after toothbrush abrasion were not significantly different from those of bovine dentin polished with \#4000-grit $\mathrm{SiC}(p>0.05)$.

\section{DISCUSSION}

A clinical strategy to prevent root caries has not been established yet. The application of the coating material on root surface is a promising approach to seal and protect the exposed root dentin surfaces. Therefore, this study investigated the durability of these potentially

Table 2 Nanoindentation hardness of the coating materials

\begin{tabular}{cc}
\hline Coating material & Hardness $(\mathrm{MPa})$ \\
\hline $\mathrm{SF}$ & $295.4 \pm 16.4^{*}$ \\
$\mathrm{HC}$ & $283.9 \pm 21.0^{*}$ \\
\hline
\end{tabular}

Values are $\operatorname{mean} \pm \mathrm{SD} ; n=30$. * indicates no significant difference $(p>0.05)$. protective coatings.

A number of toothbrushing simulators have been proposed in the literatures with different principles in the fundamental design ${ }^{21,22)}$. However, a consensus about the design and parameter setting for predictable toothbrush abrasion in the oral environment has not been reached. The previous clinical studies reported that the mean brushing force values applied by subjects were $2.3 \pm 0.7 \mathrm{~N}^{23)}, 267 \pm 73 \mathrm{~g}^{24)}, 2.96 \pm 0.8 \mathrm{~N}$ vertical force ${ }^{25)}$ and $330 \pm 109 \mathrm{~g}^{26)}$; therefore, the $300 \mathrm{~g}$ vertical load used as the toothbrushing force in this study was clinically relevant.

Cementum is the first layer to be encountered when the root surface is exposed to the oral environment. However, the cementum formation exists as a superficial layer on the root and is easily peeled off by intensive root planing during the treatment of periodontal diseases or by toothbrushing ${ }^{27)}$. The vulnerability of the cementum layer causes the underlying dentin to be prone to exposure, hence increasing the risk of dentin hypersensitivity and root dentin caries formation. For this reason, the chief focus of this study was on surface coating of dentin with a view to protecting exposed root dentin.

From the current results, thickness of the coating material decreased in both SF and $\mathrm{HC}$ in proportion to the frequency of toothbrush abrasion cycles. However, no significant difference was observed in abrasion regression slopes between the two materials under each test condition, which confirmed similar wear tendencies for both coatings. Generally, in the resinbased materials with additional filler particles, the filler particles in close proximity protect the softer resin-matrix from abrasion and wear ${ }^{28)}$. Therefore, a higher toothbrush wear resistance was expected in SF than in HC, because SF contains glass fillers, whereas $\mathrm{HC}$ does not contain filler particles. On the other hand, another study reported that coating materials with filler particles were considered to show complicated abrasion patterns because abrasion occurred in the resin matrix ${ }^{29)}$. Furthermore, similar hardness values were found between SF and HC in this study. While the presence of fillers is expected to contribute to the hardness of a thin-film, it should be noted that the nanoindentation test conducted at the small load of $1.5 \mathrm{mN}$ projected a small area (indentation depth 500-600 nm) on the resin

Table 3 Surface roughness of the coating materials and bovine dentin (Ra)

\begin{tabular}{ccc}
\hline & \multicolumn{2}{c}{ Surface roughness $(\mu \mathrm{m})$} \\
\cline { 2 - 3 } & Before toothbrushing & After 10,000 cycle with the slurry \\
\hline SF & $1.28 \pm 0.29^{\mathrm{a}}$ & $5.09 \pm 1.14^{\mathrm{b}}$ \\
HC & $1.17 \pm 0.31^{\mathrm{a}}$ & $4.62 \pm 1.71^{\mathrm{b}}$ \\
\hline Bovine dentin (\#4000-grit Sic) & & $4.86 \pm 1.71^{\mathrm{b}}$ \\
\hline
\end{tabular}

Values are mean $\pm \mathrm{SD} ; n=9$.

Values marked by different superscript letters are significantly different $(p<0.05)$. 
matrix, and the resulting values could greatly depend on compositional factors affecting the quality of the resin matrix ${ }^{30)}$. The hardness values obtained for both coating materials were in close agreement with those reported previously for dental adhesives ${ }^{30,31}$. Interestingly, there was an abrupt initial loss of coating thickness, especially in the toothpaste slurry groups, at the $0-1,000$ cycles for both materials, which should be attributed to the presence of an oxygen-inhibited unpolymerized layer on the cured coating materials. Methacrylate monomers polymerize following a free-radical-induced reaction, which is strongly inhibited by oxygen diffusing from the atmosphere into curing resin. The thickness of this layer can be up to a few $\mu \mathrm{m}$ from the surface, and the degree of inhibition depends on the compositional factors such as presence of fillers and viscosity of the resin, which will in turn affect the mechanical properties of the polymer ${ }^{32)}$.

The thickness of SF at the baseline was higher than that of HC. Perhaps filler particles in SF could increase the viscosity of the coating material, which may secure the film thickness of the coating material. Therefore, SF could remain on the dentin surface after 50,000 cycles of toothbrushing. On the other hand, a single coat of HC created an approximately $6 \mu \mathrm{m}$-thick layer, which could be easily worn away before 50,000 cycles. In addition, wear resistance of the coating materials was significantly influenced by the abrasion media (water or slurry with the toothpaste). The toothpaste contains $\mathrm{CaCO}_{3}$ particles as an abrasive for stain removal, which enhanced friction and accelerated wear of the resin matrix of the coating materials in both SF and HC.

In the current study, dentin surface coating with SF or $\mathrm{HC}$ before toothbrush abrasion created significantly smoother surfaces than the dentin surfaces polished with \#4000-grit SiC, which was considered to be far smoother than dentin surface achieved clinically by any root surface planing method ${ }^{33)}$. The coating after slurry abrasion did not show significantly rougher surface compared to the highly polished dentin surfaces, indicating the potential benefit of dentin surface coating in terms of surface smoothness. It has been reported that salivary pellicle absorption and biofilm formation are strongly influenced by some peculiar characteristics of the material surface such as surface roughness, surface electric charge and chemical composition ${ }^{34,35)}$. Increased roughness has been correlated with increased accumulation of dental plaque. Some in vivo studies suggested a threshold surface roughness for bacterial retention below which no further reduction in bacterial accumulation could be expected $^{36,37)}$. Furthermore, Daneshmehr et al. reported that root surface coated with the all-in-one adhesive materials created smoother surfaces than ground dentin surfaces, and reduced biofilm attachment on the surfaces compared to the uncoated dentin surfaces ${ }^{14)}$. Therefore, both of SF and HC appear to be effective root surface coating materials that can to some extent prevent biofilm formation.

The coating materials remained after 10,000 cycles abrasion in both of SF and HC, which is assumed to be simulating approximately one year of clinical toothbrush wear ${ }^{19,22)}$. However, several other factors can adversely affect the clinical retention of coating materials on the root surface. It was reported that bonded interfaces produced by adhesive systems degraded for long time in vivo due to hydrolysis or enzymatic degradation of dentin organic phase ${ }^{38}$. Therefore, further studies should be carried out to evaluate the long-term reliability of the root surface coating materials under the clinical setting.

\section{CONCLUSIONS}

The coating materials, SF and HC, wore at a similar pace under toothbrush abrasion, and remained after 10,000 cycles abrasion. SF has a thicker coat and therefore could protect dentin longer, up to 50,000 cycles.

\section{ACKNOWLEDGMENTS}

This work was supported by the Global Center of Excellence (GCOE) Program; International Research Center for Molecular Science in Tooth and Bone Diseases at Tokyo Medical and Dental University, and a Grant-in Aid from the Japan Society for the Promotion of Science (JSPS No. 22791829).

\section{REFERENCES}

1) Heijnsbroek M, Paraskevas S, Van der Weijden GA. Fluoride interventions for root caries: a review. Oral Health Prev Dent 2007; 5: 145-152.

2) Paraskevas S, Danser MM, Timmerman MF, van der Velden U, van der Weijden GA. Amine fluoride/stannous fluoride and incidence of root caries in periodontal maintenance patients. A 2 year evaluation. J Clin Periodontol 2004; 31: 965-971.

3) PeterssonLG, Hakestam U, BaigiA, Lynch E.Remineralization of primary root caries lesions using an amine fluoride rinse and dentifrice twice a day. Am J Dent 2007; 20: 93-96.

4) Papas A, He T, Martuscelli G, Singh M, Bartizek RD, Biesbrock AR. Comparative efficacy of stabilized stannous fluoride/sodium hexametaphosphate dentifrice and sodium fluoride/triclosan/copolymer dentifrice for the prevention of periodontitis in xerostomic patients: a 2-year randomized clinical trial. J Periodontol 2007; 78: 1505-1514.

5) Bartlett D, Sundaram G, Moazzez R. Trial of protective effect of fissure sealants, in vivo, on the palatal surfaces of anterior teeth, in patients suffering from erosion. J Dent 2011; 39: 2629.

6) Nikaido T, Nakaoki Y, Ogata M, Foxton R, Tagami J. The resin-coating technique. Effect of a single-step bonding system on dentin bond strengths. J Adhes Dent 2003; 5: 293300.

7) Kosaka S, Kajihara H, Kurashige H, Tanaka T. Effect of resin coating as a means of preventing marginal leakage beneath full cast crowns. Dent Mater J 2005; 24: 117-122.

8) Islam MR, Takada T, Weerasinghe DS, Uzzaman MA, Foxton RM, Nikaido T, Tagami J. Effect of resin coating on adhesion of composite crown restoration. Dent Mater J 2006; 25: 272 279.

9) Ariyoshi M, Nikaido T, Foxton RM, Tagami J. Microtensile bond strengths of composite cores to pulpal floor dentin with resin coating. Dent Mater J 2008; 27: 400-407.

10) Takahashi R, Nikaido T, Ariyoshi M, Kitayama S, Sadr A, Foxton RM, Tagami J. Thin resin coating by dual-application of all-in-one adhesives improves dentin bond strength of resin cements for indirect restorations. Dent Mater J 2010; 29: 615- 
622.

11) Sundaram G, Wilson R, Watson TF, Bartlett D. Clinical measurement of palatal tooth wear following coating by a resin sealing system. Oper Dent 2007; 32: 539-543.

12) Inoue G, Tsuchiya S, Nikaido T, Foxton RM, Tagami J. Morphological and mechanical characterization of the acidbase resistant zone at the adhesive-dentin interface of intact and caries-affected dentin. Oper Dent 2006; 31: 466-472.

13) Waidyasekera $K$, Nikaido $T$, Weerasinghe DS, Ichinose $\mathrm{S}$, Tagami J. Reinforcement of dentin in self-etch adhesive technology: a new concept. J Dent 2009; 37: 604-609.

14) Daneshmehr L, Matin K, Nikaido T, Tagami J. Effects of root dentin surface coating with all-in-one adhesive materials on biofilm adherence. J Dent 2008; 36: 33-41.

15) Tajima K, Nikaido T, Inoue G, Ikeda M, Tagami J. Effects of coating root dentin surfaces with adhesive materials. Dent Mater J 2009; 28: 578-586.

16) Yu X, Liang B, Jin $\mathrm{X}, \mathrm{Fu} B$, Hannig M. Comparative in vivo study on the desensitizing efficacy of dentin desensitizers and one-bottle self-etching adhesives. Oper Dent 2010; 35: 279286.

17) Attin T, Buchalla W, Hellwig E. Effect of topical fluoride application on toothbrushing abrasion of resin composites. Dent Mater 2006; 22: 308-313.

18) Yu H, Wegehaupt FJ, Wiegand A, Roos M, Attin T, Buchalla W. Erosion and abrasion of tooth-colored restorative materials and human enamel. J Dent 2009; 37: 913-922.

19) Suzuki T, Kyoizumi H, Finger WJ, Kanehira M, Endo T, Utterodt A, Hisamitsu H, Komatsu M. Resistance of nanofill and nanohybrid resin composites to toothbrush abrasion with calcium carbonate slurry. Dent Mater J 2009; 28: 708-716.

20) Carvalho F, Sampaio C, Fucio S, Carlo H, Correr-Sobrinho L, Puppin-Rontani R. Effect of chemical and mechanical degradation on surface roughness of three glass ionomers and a nanofilled resin composite. Oper Dent 2012; 37: 509-517.

21) Wang L, Garcia FC, Amarante de Araujo P, Franco EB, Mondelli RF. Wear resistance of packable resin composites after simulated toothbrushing test. J Esthet Restor Dent 2004; 16: 303-314.

22) Parry J, Harrington E, Rees GD, McNab R, Smith AJ. Control of brushing variables for the in vitro assessment of toothpaste abrasivity using a novel laboratory model. J Dent 2008; 36 : 117-124.

23) Ganss C, Schlueter N, Preiss S, Klimek J. Tooth brushing habits in uninstructed adults -frequency, technique, duration and force. Clin Oral Investig 2009; 13: 203-208.

24) van der Weijden GA, Timmerman MF, Reijerse E, Snoek CM, van der Velden U. Toothbrushing force in relation to plaque removal. J Clin Periodontol 1996; 23: 724-729.
25) Boyd RL, McLey L, Zahradnik R. Clinical and laboratory evaluation of powered electric toothbrushes: in vivo determination of average force for use of manual and powered toothbrushes. J Clin Dent 1997; 8: 72-75.

26) Van der Weijden GA, Timmerman MF, Danser MM, Van der Velden U. Relationship between the plaque removal efficacy of a manual toothbrush and brushing force. J Clin Periodontol 1998; 25: 413-416.

27) Ritz L, Hefti AF, Rateitschak KH. An in vitro investigation on the loss of root substance in scaling with various instruments. J Clin Periodontol 1991; 18: 643-647.

28) Cavalcante LM, Masouras K, Watts DC, Pimenta LA, Silikas N. Effect of nanofillers' size on surface properties after toothbrush abrasion. Am J Dent 2009; 22: 60-64.

29) Eneren ES, Imazato S, Kaneshiro AV, Iwami Y, Ebisu S, Gurgan S. Resistance of surface coating resins against toothbrushing abrasion. Am J Dent 2010; 23: 70-74.

30) Sadr A, Ghasemi A, Shimada Y, Tagami J. Effects of storage time and temperature on the properties of two self-etching systems. J Dent 2007; 35: 218-225.

31) Sadr A, Shimada Y, Lu H, Tagami J. The viscoelastic behavior of dental adhesives: a nanoindentation study. Dent Mater 2009; 25: 13-19.

32) Gauthier MA, Stangel I, Ellis TH, Zhu XX. Oxygen inhibition in dental resins. J Dent Res 2005; 84: 725-729.

33) Ota-Tsuzuki C, Martins FL, Giorgetti AP, de Freitas PM, Duarte PM. In vitro adhesion of Streptococcus sanguinis to dentine root surface after treatment with Er:YAG laser, ultrasonic system, or manual curette. Photomed Laser Surg 2009; 27: 735-741.

34) Sipahi C, Anil N, Bayramli E. The effect of acquired salivary pellicle on the surface free energy and wettability of different denture base materials. J Dent 2001; 29: 197-204.

35) Steinberg D, Eyal S. Early formation of Streptococcus sobrinus biofilm on various dental restorative materials. J Dent 2002; 30: 47-51.

36) Quirynen M, Bollen CM, Papaioannou W, Van Eldere J, van Steenberghe D. The influence of titanium abutment surface roughness on plaque accumulation and gingivitis: short-term observations. Int J Oral Maxillofac Implants 1996; 11: 169178.

37) Bollen CM, Papaioanno W, Van Eldere J, Schepers E, Quirynen M, van Steenberghe D. The influence of abutment surface roughness on plaque accumulation and peri-implant mucositis. Clin Oral Implants Res 1996; 7: 201-211.

38) Walter R, Swift EJ Jr, Nagaoka H, Chung Y, Bartholomew W, Braswell KM, Pereira PN. Two-year bond strengths of "all-in-one" adhesives to dentine. J Dent 2012; 40: 549-555. 